ECONOMía: TeORía y PrÁctica • Nueva Época, número 45, julio-diciembre 2016, pp. 5-37, http://www.izt.uam.mx/economiatyp/ojs

\title{
Inserción en cadenas de valor globales y patrones de innovación de empresas de países en desarrollo: las pymes de Argentina*
}

\section{Global Value Chains and Innovation Patterns in Developing Countries: The SMEs in Argentina}

\author{
Matías E. Mancini**
}

\begin{abstract}
RESUMEN
La segmentación internacional de los procesos productivos y la conformación de sistemas globales de producción han generado nuevos desafíos para las pymes de los países en desarrollo. Los estudios sobre cadenas de valor globales han señalado las oportunidades y los obstáculos para mejorar las capacidades de aquéllas en las actividades (como ID y diseño) que conforman las competencias clave de las empresas transnacionales. Los estudios empíricos que analizan, a partir de encuestas de innovación, la asociación de la inserción internacional con los procesos de innovación de las firmas no consideran estos aportes. Con base en una muestra de pymes de Argentina, se intenta integrar ambos enfoques diferenciando los distintos patrones de innovación de las pymes y analizando cómo la inserción en las cadenas globales afecta el tipo de dichos patrones. Asociado a esto, se las posibilidades de upgrading de estas empresas.
\end{abstract}

Palabras clave: pymes argentinas, cadenas de valor globales, upgrading, países en desarrollo, innovación.

Clasificación JEL: O120, D210, F610, L600.

\begin{abstract}
The international fragmentation of production and the emergence of global production systems have created new challenges for SMES in developing countries. The literature of global value chains has indicated the opportunities and obstacles to improve skills in activities (such as R\&D and design) that define the multinational companies' core competencies. Micro empirical studies which analyze the association between international integration and firm's innovation activities, do not consider this contributions. Based on a sample of Argentinian SMEs, this paper attempts to integrate the two approaches through a differentiation of the various innovation patterns of the SMEs. A model is estimated to examine if the integration into global value chains affects the type of innovation patterns. Through this model, upgrading opportunities for firms from developing countries are analyzed.
\end{abstract}

Keywords: Argentine SMEs, global value chains, upgrading, developing countries, innovation.

JEL classification: O120, D210, F610, L600.

* Fecha de recepción: 04/02/2014. Fecha de aprobación: 31/05/2016.

** Centro de Estudios Urbanos y Regionales del Consejo Nacional de Investigaciones Científicas y Técnicas, Argentina. Correo electrónico: matiasmancini@gmail.com. 
6 ECONOMÍA: TEORÍA Y PRÁCTICA • Nueva Época, número 45, julio-diciembre 2016

\section{INTRODUCCIÓN}

Como consecuencia de las estrategias de externalización de las empresas trasnacionales, en los últimos decenios se asiste a una reconfiguración de la economía mundial a través de la segmentación internacional de los procesos productivos y la conformación de sistemas globales de producción. Estos fenómenos han despertado la atención de ciertos autores que adoptan la noción de cadenas de valor globales (CVG) para el estudio de la nueva división internacional del trabajo asociada a los procesos de globalización de la producción (Gereffi, Humphrey y Sturgeon, 2005). Entre sus aportes, la literatura sobre CVG ha analizado las posibilidades y obstáculos que enfrentan las empresas de los países en desarrollo insertas en las cadenas globales para mejorar su posición (upgrading o escalamiento) en las industrias globales. Al resaltar las dinámicas asimétricas que distinguen a las cadenas y el papel de las trasnacionales como coordinadoras de las distintas actividades, el enfoque de CVG trae a discusión las implicaciones de los procesos de segmentación internacional para las posibilidades de aprendizaje de las empresas de los países en desarrollo. Si bien los sistemas globales de producción pueden crear oportunidades para que éstas aumenten sus capacidades tecnológicas y se integren a la economía global, la literatura especializada también ha señalado que pueden enfrentar obstáculos para mejorar sus capacidades en las áreas que constituyen las competencias clave del capital trasnacional y que se vinculan con la investigación y desarrollo (ID) y el diseño de nuevos productos.

No obstante su importancia, estos fenómenos no han sido contemplados en los trabajos que con base en microdata examinan empíricamente los efectos de la inserción internacional sobre la dinámica innovadora de las empresas, por ejemplo, Salomon y Shaver (2005); Almeida y Fernandes (2008); Crespi, Criscuolo y Haskel (2008), Damijan, Kostevc y Polanec (2010), y Criscuolo, Haskel y Slaughter (2010). Estos trabajos se desentienden de la influencia que pueden tener las formas que adoptan las relaciones entre los actores involucrados en el comercio mundial sobre la acumulación de nuevas capacidades y la difusión de tecnología y, por consiguiente, de las implicaciones para el desarrollo de las empresas en las naciones en desarrollo.

Frente a esta limitación, y apoyándose en los aportes de la literatura sobre CVG, el presente trabajo busca analizar cómo la inserción en estas cadenas afecta el tipo de patrones de innovación que desarrollan las pymes de los países en desarrollo y, asociado a ello, discutir cuáles son sus posibilidades de upgrading. Para esto, se recurre a una muestra de pymes de Argentina con informa- 
ción, principalmente, del año 2006. Se intenta dilucidar si las pymes argentinas insertas en CVG se enfocan en un patrón de actividades de innovación destinado a mejorar los procesos productivos a fin de incrementar su eficiencia, pero con limitados avances en la acumulación de nuevas capacidades relacionadas con la ID y el diseño de productos. En este caso, el patrón de actividades de innovación estaría en consonancia con un perfil de inserción internacional basado preferentemente en la producción de manufacturas, de acuerdo a los parámetros de producción desarrollados por las trasnacionales en los países centrales.

Luego de esta introducción, la primera sección describe el marco teórico sustentado en los aportes de la literatura sobre CVG y expone críticamente los trabajos empíricos a nivel de empresas que analizan los efectos de la inserción internacional sobre su dinámica de innovación. En la segunda parte se presenta la metodología empleada para analizar los vínculos entre la inserción en CVG y los patrones de innovación de las pymes argentinas, se explica la construcción de los principales indicadores utilizados y se describe el modelo econométrico propuesto. En la tercera sección se muestran los resultados obtenidos. Por último, se presentan las reflexiones finales.

\section{MARCo TeÓRICO}

\section{El enfoque de cadenas de valor globales}

Desde los años ochenta se asiste a cambios en la economía mundial moldeados por el paso de una estrategia global integrada hacia una estrategia de segmentación vertical por parte de las empresas trasnacionales. ${ }^{1}$ A través de operaciones de externalización y subcontratación internacional, aquéllas han profundizado la interdependencia y la integración funcional entre actividades, las cuales son llevadas a cabo en distintas localizaciones, desbordando las fronteras nacionales (Chesnais, 1988; Gereffi, 1999; Kaplinsky, 2000; Lavarello, 2004; Gereffi, Humphrey y Sturgeon, 2005). Como consecuencia de esta segmentación de la producción global, ha crecido el peso de los componentes y los bienes intermedios en el comercio internacional (Feesnstra, 1998).

\footnotetext{
${ }^{1}$ La consideración sobre el cambio de estrategias multidomésticas a estrategias globales ya estaba presente en la literatura sobre las trasnacionales de los años ochenta (Porter, 1986; Dunning, 1995), que enfocaba su análisis en la estructura organizacional y la coordinación de las actividades dispersas a escala internacional. En este sentido, el punto novedoso que trae a discusión la teoría de CVG es la externalización de ciertas actividades a través de operaciones de subcontratación internacional.
} 
Las razones de esto obedecen al proceso de reestructuración de las estrategias de las trasnacionales (Andreff, 2009). Hasta los años sesenta, la organización de la producción de estas empresas respondía al paradigma fordista compañías verticalmente integradas. A partir de entonces, su estrategia ha virado hacia la racionalización y la externalización de actividades antes desarrolladas internamente, concentrándose así en sus competencias clave (Langlois, 2003). Este proceso ha sido facilitado por los cambios en las tecnologías de coordinación tras el surgimiento de las nuevas tecnologías de la información y la comunicación. Al reducir los costos de transacción internos de las cadenas de valor, estas nuevas tecnologías permiten la conformación de sistemas de producción modulares y la integración de la producción a escala global.

De acuerdo con Lavarello (2004), las nuevas estrategias de las trasnacionales obedecen a una nueva etapa de mundialización del capital caracterizada por la subordinación de su proceso de acumulación a los requisitos de la valorización financiera. A partir de los ochenta, con el impulso de reformas para liberalizar y desregular los mercados de capitales, el capital financiero se apropia del excedente generado en la esfera productiva, condicionando las estrategias de las trasnacionales y produciendo cambios en su estructura organizacional. Como resultado de las transformaciones institucionales y políticas, se generan las condiciones para que los objetivos de los gerentes de las transnacionales se alineen con los principios de gobierno corporativo de los accionistas minoritarios, quienes ejercen una influencia creciente en las estrategias de las compañías. De este modo, y bajo la presión de los accionistas para reducir la inmovilización del capital, se dan modificaciones en su estructura organizacional: se concentran en las denominadas actividades centrales, al mismo tiempo que se redistribuyen los beneficios vía dividendos o mediante la inflación accionaria que valoriza los activos de los inversores institucionales.

La concentración en las actividades centrales permite a las trasnacionales especializarse en los segmentos de la cadena de valor con menor presión competitiva y mayores posibilidades de apropiación de rentas extraordinarias basadas en la innovación (Kaplinsky y Morris, 2001). Desde mediados de los ochenta, en coincidencia con el surgimiento de China como productor de manufacturas con bajos costos salariales y el consiguiente aumento de las presiones competitivas en la fase de producción de la cadena de valor, se observa una caída en los términos de intercambio de los bienes exportados por los países en desarrollo (Kaplinsky, 2000). Se trata de las manufacturas más simples y/o con mayores posibilidades de estandarización. En este sentido, Gereffi et al. (2001) 
agregan que las mejoras en las capacidades de producción de las empresas de dichos países han provocado una conversión de las manufacturas en mercancías genéricas (commodities): producción de volúmenes altos con precios bajos y reducidos márgenes de beneficio.

Dado que el proceso de globalización productiva implica que cada eslabón de la cadena se localice en distintos países, surge el interrogante de cómo coordinar las distintas actividades involucradas. El punto clave es que al externalizar ciertas funciones de la cadena, las trasnacionales no sacrifican el control del proceso de producción. Al respecto, la literatura de CVG utiliza el concepto de gobernanza (governance) para definir las relaciones de autoridad que determinan cómo se asignan los recursos financieros, materiales y humanos, y cómo fluyen éstos dentro de la cadena (Gereffi, 1994; Gereffi, Humphrey y Sturgeon, 2005). Este concepto permite, entonces, describir el control (no asociado necesariamente a la propiedad directa) que ejerce una empresa sobre el resto de las firmas que participan en la producción de un bien final, desde la primera hasta la última fase en la cadena de valor.

En coincidencia con el enfoque de costos de transacción de Williamson (1979), este patrón de organización industrial en el que una empresa líder ejerce la coordinación de la cadena se presentaría como un caso intermedio entre relaciones estrictamente de mercado y la integración vertical o propiedad directa. Este abordaje permite, entonces, ampliar la gama de posibles formas de gobernanza en las cadenas de valor, planteando la existencia de dos casos polares (relaciones de mercado e integración vertical) y diversas modalidades intermedias.

A partir de la evidencia empírica, Gereffi, Humphrey y Sturgeon (2005) proponen una tipología de formas de gobernanza en las CVG que distingue entre:

1) Relaciones de mercado: no existe necesidad de coordinación explícita, ya que la información involucrada en las transacciones entre las partes es fácilmente codificable, las especificaciones del producto son simples, los bienes comercializados están estandarizados y los proveedores poseen las capacidades necesarias.

2) Cadena de valor modular: los proveedores poseen la capacidad de producir módulos (full packages) sin necesidad de control directo o monitoreo por parte del comprador, ya que sus productos son complejos, pero existe la posibilidad de codificar el conocimiento a través de estándares técnicos.

3) Cadena de valor relacionada: las capacidades requeridas para la producción son significativas y las especificaciones del producto son complejas, pero en 
este caso no pueden ser codificadas, generándose una dependencia mutua usuario-proveedor (generalmente basada en la reputación y la confianza).

4) Cadena de valor cautiva: los productos son complejos y existen posibilidades de codificación del conocimiento, pero como las capacidades técnicas de los productores son bajas, la trasnacional ejerce un gran control sobre los proveedores (y posiblemente sobre su capacitación), generando una dependencia transaccional.

5) Cadena jerárquica: modelo clásico de integración vertical adoptado por las empresas transnacionales durante la fase de internacionalización del capital, con el establecimiento de plantas subsidiarias del tipo réplica (que reproduce las líneas de producción de la casa matriz, pero a escala más reducida).

Por su parte, Humphrey y Schmitz (2002) proponen otra clasificación con idénticos casos polares de gobernanza (mercado e integración vertical), pero en la que los intermedios son sólo dos: relaciones cuasi jerárquicas y redes. Las cadenas basadas en redes implican competencias complementarias y tareas de cooperación entre las partes. En cambio, en las relaciones cuasi jerárquicas, las trasnacionales ejercen un gran control sobre otras firmas de la cadena, generalmente especifican las características del producto y de los métodos de proceso, contribuyen a que los productores alcancen las capacidades necesarias y establecen, a su vez, mecanismos de control para asegurar el cumplimiento de dichas especificaciones. De acuerdo con Gereffi, Humphrey y Sturgeon (2005, p. 83), las relaciones cuasi jerárquicas corresponderían a las denominadas cautivas en su tipología.

La globalización de los sistemas de producción y las formas de coordinación correspondientes tienen implicaciones directas sobre las posibilidades de desarrollo de las pymes de los países en desarrollo. Por ello, en el marco de la teoría de CVG, se acuñó el concepto de upgrading (escalamiento) para describir las mejoras de las competencias y de la posición de las empresas en las industrias globales.

De acuerdo con Gereffi et al. (2001) y Humphrey y Schmitz (2002) pueden distinguirse tres tipos de upgrading: de proceso, que se refiere a la transformación más eficiente de insumos en productos a través del uso de una tecnología superior o mediante la reorganización de los sistemas de producción; de producto, que es el desplazamiento hacia líneas de productos más sofisticados, y el funcional, cuando las firmas pueden adquirir funciones más complejas en la cadena de valor, relacionadas con actividades que permiten una mayor generación y apropiación de rentas basadas en la innovación. 
Asimismo, la literatura sobre CVG ha señalado la existencia de una trayectoria acumulativa de mejoras en las capacidades, que partiría de un upgrading de proceso para llegar a uno de producto $\mathrm{y}$, finalmente, a uno funcional. Esta trayectoria está conformada por las siguientes etapas: 1) ensamblado de componentes importados, 2) fabricación de manufacturas con el desarrollo y la integración progresiva de proveedores locales, 3) diseño de productos pero con marcas internacionales (fabricantes de equipos originales u OEM, por sus siglas en inglés), y 4) el upgrading funcional, cuando se poseen capacidades de ID y diseño suficientes que permiten el desarrollo de marcas propias. ${ }^{2}$

La progresión en las últimas etapas es la más complicada. Dado que el upgrading funcional invade las competencias clave de compradores globales, los productores de los países en desarrollo pueden enfrentar obstáculos y ver limitadas las transferencias de tecnología y el desarrollo de capacidades en estas áreas. Por ejemplo, Schmitz y Knorringa (2000) encontraron que en la cadena mundial de calzado los compradores globales han desalentado, e incluso obstruido, el diseño, la comercialización y el desarrollo de nuevas marcas por parte de productores de China, India, Brasil e Italia. A su vez, Giuliani, Pietrobelli y Rabellotti (2005) estudiaron cuarenta conglomerados latinoamericanos encontrando que la inserción en CVG a menudo incentiva el upgrading de producto y de proceso debido a la presión para cumplir con los estándares impuestos por las empresas líderes. Sin embargo, salvo excepciones, esta inserción inhibe el funcional.

En el caso de la tipología de formas de coordinación propuesta por Humphrey y Schmitz (2002), estos autores concluyen que: 1) la inserción en una cadena de tipo cuasi jerárquica (o cautiva) ofrece condiciones favorables para el upgrading de proceso y de producto, pero dificulta el funcional, y 2) en cadenas caracterizadas por relaciones independientes de mercado, las posibilidades de upgrading de producto y de proceso tienden a ser menores que en el caso anterior, ya que no se fomentan por las empresas líderes, pero el logro del funcional es más factible. En general, la evidencia recolectada por los estudios de caso sugiere que las empresas de los países en desarrollo encuentran dificultades para mejorar su posición en las CVG, en cualquiera de las vías propuestas (Bair, 2005). Esto se debe a las barreras que encuentran dichas empresas para moverse hacia aquellas actividades de la cadena que son centrales para las compañías líderes.

\footnotetext{
${ }^{2}$ Esta trayectoria de upgrading progresivo en las CVG Correspondería a la experiencia de países asiáticos como Corea del Sur y Taiwán en la industria de textiles y de productos electrónicos (Gereffi, 1999; Kaplinsky y Morris, 2001).
} 
En síntesis, los procesos de internacionalización productiva y la conformación de CVG han generado nuevos retos y oportunidades para el desarrollo de las empresas y los sectores de países en desarrollo. Por un lado, los cambios en la división internacional del trabajo derivados de las estrategias de externalización de las trasnacionales brindarían mayores oportunidades a las firmas ubicadas en la periferia para insertarse en actividades más dinámicas -es decir, más intensivas en el uso y la difusión de conocimiento tecnológico- a través de una estrategia paulatina de acumulación de capacidades (Memedovic, 2004; BID, 2014). Por otro lado, la retención de las actividades de ID en las casas matrices de las transnacionales conllevaría una continuidad en la dependencia tecnológica de los países en desarrollo respecto a los centros industriales. En este contexto, el estudio de los procesos de innovación y adopción de nuevas capacidades por parte de las pymes que se insertan en la economía global permite una aproximación a la cuestión de cuál de los dos fenómenos predomina.

\section{Estudios sobre la asociación entre el comercio internacional y la innovación a nivel de la empresa: argumentos teóricos y evidencia empírica}

Ciertos trabajos de naturaleza empírica han analizado la relación existente entre los procesos de innovación a nivel de las firmas y su integración en la economía global (Salomon y Shaver, 2005; Almeida y Fernandes, 2008; Crespi, Criscuolo y Haskel, 2008; Gonçalves, Borges y De Negri, 2008; Criscuolo, Haskel y Slaughter, 2010; Damijan, Kostevc y Polanec, 2010; Gorodnichenko, Svejnar y Terrell 2010). La exploración empírica de estos trabajos se sustenta en una serie de argumentos teóricos que sostienen la existencia de efectos positivos de los vínculos globales de las empresas sobre sus posibilidades de aprendizaje.

Respecto a las exportaciones, las firmas que venden en mercados externos pueden verse beneficiadas por el efecto denominado learning by exporting (Clerides, Lach y Tybout, 1998). ${ }^{3}$ Por otro lado, mediante ingeniería inversa, las empresas de países en desarrollo que se proveen en mercados externos pueden aprender de la tecnología incorporada que no se encuentra disponible en su mercado doméstico, lo que también impactaría en sus actividades innovadoras (Keller, 2004).

\footnotetext{
${ }^{3}$ Los mecanismos por los cuales puede darse este efecto son: el acceso a conocimientos no disponibles en el mercado doméstico (sobre nuevos productos, requerimientos de los usuarios y/o tecnologías utilizadas), los incentivos para mejorar la calidad o el cumplimiento de ciertos requisitos ante la mayor presión competitiva.
} 
Más allá de ciertas discrepancias metodológicas y teóricas entre estos trabajos (por ejemplo en torno a dónde se reflejan las ventajas de comerciar en mercados extranjeros) ${ }^{4}$ y cierta variedad en los resultados obtenidos, en general la evidencia internacional sugiere la existencia de un efecto positivo de la inserción comercial mundial sobre la innovación (Salomon y Shaver, 2005; Almeida y Fernandes, 2008; Crespi, Criscuolo y Haskel, 2008). En lo que respecta a América Latina, Gonçalves, Borges y De Negri (2008) encuentran que la inserción internacional tiene gran importancia para la realización de innovaciones en las empresas argentinas y brasileñas, aunque es mucho más relevante para las primeras. Sin embargo, mientras en Brasil las exportaciones son fundamentales para la innovación en productos, en Argentina desempeñan un rol más significativo en las innovaciones de proceso.

Otro antecedente sobre empresas argentinas es el trabajo de Chudnovsky, López y Pupato (2006). Estos autores encuentran que la inserción exportadora influye en los resultados innovadores (producto o proceso), pero no en las actividades y esfuerzos que desarrollan para lograrlos. Este resultado contradice el de Crespi y Zuñiga (2012), quienes encuentran que en Argentina las exportaciones aumentan las probabilidades de que las firmas realicen esfuerzos innovadores, pero sin evidencia significativa de que aquéllas tengan impacto sobre las innovaciones de producto o proceso.

Con base en los aportes del enfoque de CVG, pueden señalarse ciertas limitaciones de estos trabajos empíricos. En primer lugar, carecen de una consideración acabada del proceso de globalización productiva y las implicaciones de los cambios en la división internacional del trabajo. En estos estudios, la inserción en la economía global se reduce a las relaciones comerciales. Como se ha mencionado, un análisis de los procesos de innovación de las pymes debería contemplar el modo de incorporación de estas empresas al marco de la reestructuración de la organización industrial mundial. Esto está estrechamente ligado con una segunda limitación: la ausencia de una discriminación de las actividades de innovación. En general, se estudian los factores determinantes de la innovación contemplando indistintamente el desarrollo de nuevos productos o la adop-

\footnotetext{
${ }^{4}$ Algunos trabajos consideran que el comercio internacional debería reflejarse en mejoras de la productividad de la empresas (Bernard y Jensen, 1999), en las actividades o esfuerzos de innovación (Kumar y Aggarwal, 2005) o directamente en los resultados de innovación (Salomon y Shaver, 2005; Gonçalves, Borges y De Negri, 2008; Almeida y Fernandes, 2008). Además, algunos autores buscan medir cómo las exportaciones abren posibilidades de aprendizaje a partir de la interacción con los compradores (Crespi, Criscuolo y Haskel, 2008).
} 
ción de nuevas técnicas de producción. Los resultados de Gonçalves, Borges y De Negri (2008), que asocian la exportación exclusivamente con innovaciones de proceso en el caso de las empresas de Argentina, constituyen un antecedente válido para argumentar que los vínculos internacionales pueden relacionarse con ciertos patrones específicos de innovación.

\section{Reflexiones sobre el marco teórico y la pregunta de investigación}

El estudio sobre las posibilidades de progreso competitivo y la acumulación de nuevas capacidades por las empresas de los países en desarrollo no puede desasociarse de los cambios sucedidos a escala global en la organización industrial por las nuevas estrategias de segmentación de las transnacionales. En este marco, surge la pregunta sobre cuáles son las posibilidades que tienen las empresas de los países en desarrollo de participar activamente en las CVG, promoviendo procesos de mejoras tecnológicas y de diversificación productiva. Ciertas investigaciones sostienen que la mayor segmentación internacional de los procesos productivos ofrece oportunidades a los países periféricos para reducir las brechas tecnológicas, exportar productos de alto valor agregado y mejorar las capacidades tecnológicas (Memedovic, 2004; BID, 2014). Otros estudios son más escépticos sobre estas posibilidades, con el argumento de que las trasnacionales, al coordinar las CVG, pueden obstaculizar las mejoras en aquellos segmentos de la cadena que constituyen sus competencias clave.

No obstante, la literatura que ha examinado empíricamente la conducta innovadora de las firmas y su relación con los vínculos externos no contempla en profundidad esta discusión. Al utilizar un enfoque que privilegia la presencia de relaciones simétricas entre los agentes del comercio mundial, se desentiende de las formas que adoptan las relaciones entre los diversos actores involucrados y cómo esto afecta la acumulación de nuevas capacidades y la difusión de tecnología. El análisis del rol de la inserción de una empresa en los mercados globales debe considerar que los flujos de exportación e importación reflejan los grados de integración productiva de la empresa con la economía global.

La teoría de CVG brinda elementos útiles para explicar el desarrollo industrial y la innovación en empresas de países en desarrollo dentro de un contexto de creciente globalización y conformación de redes transnacionales entre firmas. El desarrollo de capacidades tecnológicas y los esfuerzos específicos a nivel de empresas deben analizarse en el marco de los factores contextuales asociados a las CVG que promueven o limitan estos procesos (Morrison, Pietrobelli y 
Rabellotti, 2008). Al respecto, la literatura de CVG ha resaltado que la inserción de una pyme en la economía global puede influir en sus actividades de innovación. Luego, la discusión no se centra en las posibilidades de aprendizaje de una firma que coloca parte de su producción en mercados externos (learning by exporting), sino en analizar cómo la participación en redes internacionales de producción condiciona las vías de adquisición de nuevas capacidades por las empresas de los países en desarrollo.

Teniendo en cuenta las lecciones de la literatura sobre CVG y recuperando, a su vez, los aportes metodológicos de los trabajos estadísticos a nivel de empresas, una forma de sortear parte de las limitaciones de los análisis empíricos consiste en examinar los efectos de la inserción internacional sobre cada dimensión del rango completo de actividades de innovación. La distinción entre diferentes clases de esfuerzos innovadores permitirá analizar las posibilidades de upgrading considerando la tipología propuesta por la literatura sobre CVG (de proceso, de producto y funcional). ${ }^{5}$

En este marco, se entiende que es relevante investigar qué patrones de innovación desarrollan las pymes insertas en CVG y, asociado a ello, cuáles son las posibilidades de upgrading de estas empresas. En particular, y apoyándose en la evidencia sobre pymes argentinas, se busca analizar si existe una inserción dinámica caracterizada por la adquisición de nuevas de capacidades y funciones más complejas de la cadena de valor (upgrading en el terreno de las capacidades) o si, en cambio, predominan trayectorias enfocadas en mejoras progresivas de los procesos productivos de forma que incrementen su eficiencia, con escasos avances en la adquisición de nuevas capacidades relacionadas con la investigación, el desarrollo y el diseño de productos. En este último caso, la inserción en las CVG limitaría la posibilidad de avanzar hacia un upgrading funcional.

\section{METOdología Y FUENTE de INFORMACión UTILIZAdA}

\section{Fuente de información}

La base de la información del presente trabajo consiste en una muestra de pymes industriales de Argentina con datos correspondientes, en general, a los años 2005

\footnotetext{
${ }^{5}$ Como antecedente de este esfuerzo de integración, cabe citar el trabajo de Pietrobelli y Saliola (2008). No obstante, estos autores buscan medir la forma de gobernanza de las cadenas y analizan econométricamente cómo ésta afecta la productividad de los proveedores de países en desarrollo.
} 
y 2006, que fue suministrada por el programa MAPAPYME. ${ }^{6}$ Luego de descartar los casos en que no existía toda la información necesaria para realizar la investigación, se obtuvo una base de 2486 empresas industriales.

\section{Metodología}

\section{a) Construcción de los principales indicadores utilizados}

A partir de los datos sobre las actividades innovadoras de las pymes, el primer paso consistió en identificar cuáles son los distintos patrones de actividades de innovación que siguen estas empresas. A tal fin, se recurre a un análisis de componentes principales (ACP) que permite resumir la información brindada por un conjunto de variables a través de su agrupamiento en un número de componentes (menor al número de variables originales), cada uno de los cuales es una combinación lineal de las variables originales. En el marco de la presente investigación, se reúne un conjunto de variables que indican la realización o no de cierta actividad de innovación (tecnología de producto, tecnología de proceso, diseño, calidad, organización, capacitación, comercialización, investigación y desarrollo de producto) en una serie de componentes, cada uno de los cuales representa un subconjunto de estas actividades. ${ }^{7}$

La ventaja de proceder a partir de un ACP consiste en que, en lugar de suponer patrones de innovación ad-hoc y, posteriormente, comprobar de forma estadística su significación, se realiza un análisis exploratorio de los datos de la muestra. De esta manera, es posible encontrar distintos patrones de actividades de innovación que surgen de los datos disponibles. Además, el ACP brinda una medida de cada uno de los componentes para cada empresa, es decir, de la intensidad con que cada empresa sigue cada uno de los patrones de innovación.

\footnotetext{
${ }^{6}$ El Monitoreo Aplicado a Pequeñas y Medianas Empresas (MAPAPYME) fue realizado por la Subsecretaría de la Pequeña y Mediana Empresa y Desarrollo Regional, dependiente del Ministerio de Producción de la Nación, con el objetivo de recopilar información relativa a las características de las pymes argentinas. El MAPAPYME realizó seis trabajos de campo entre 2007 y 2009, recabando datos del periodo 2006-2008, con representatividad sectorial y geográfica. Los relevamientos se publicaron en soporte electrónico (CD) con la metodología y los formularios implementados. El acceso a la base de datos usuaria se enmarca en la Ley 17.622, artículo 10, respetando la confidencialidad de la información.

${ }^{7}$ Debe tenerse en cuenta que las empresas se autoevalúan. En consecuencia, el problema de trabajar con encuestas es que aquéllas pueden no tener claridad sobre cuándo realizan o no realmente cierta actividad innovativa.
} 
Con los resultados obtenidos de este modo, el segundo paso fue clasificar las empresas de acuerdo con la intensidad de cada patrón. Esto se realizó con base en un análisis de conglomerado. Así, se identifican grupos de empresas con patrones de innovación similares al interior de cada grupo, pero diferentes entre grupos. Cada uno de éstos representa una trayectoria distintiva de actividades de innovación. Los resultados obtenidos en la sección III. 2 mostrarán que pueden distinguirse cuatro trayectorias de innovación en las pymes argentinas: 1) orientada a innovaciones no tecnológicas, 2) orientada a innovaciones en mejoras tecnológicas de proceso y de producto, 3) orientada a innovaciones de ID y diseño y 4) orientada a innovaciones no tecnológicas, a mejoras de proceso y de producto y a actividades de ID y diseño.

En tercer lugar, se construyó una variable que permitiera discriminar las pymes según su forma de inserción en tramas productivas. En función del marco teórico, se confeccionó una tipología de diferentes formas de inserción a partir del tipo de relaciones económicas proveedor-cliente en el espacio nacional o internacional (Mancini y Lavarello, 2011). La tipología considera cuatro formas de vinculación vertical a la cadena de valor:

1) Ensamble para el mercado interno. Esta forma de inserción se distingue en general por la presencia de mercados protegidos que incentivan la fabricación en el territorio nacional de manufacturas a través del armado de componentes importados. Las pymes locales, entonces, se limitarán al ensamble de conjuntos o subconjuntos para el mercado doméstico, lo que generaría pocas posibilidades de aprendizaje local y de encadenamientos y complementariedades productivas con otras ramas de la industria nacional. No obstante, sus actividades de innovación podrían verse influenciadas a través de la tecnología incorporada en los insumos y bienes intermedios importados. El interés en esta forma de inserción radica en dilucidar si las empresas se dedican con exclusividad al armado de conjuntos o subconjuntos o si avanzan en procesos de ingeniería inversa y aprendizaje.

2) Cadena de valor global. Abarca empresas que se insertan en una red internacional de aprovisionamiento y de exportación de productos semielaborados, a partir de ciertas ventajas de localización (acceso a mano de obra con bajos salarios, recursos naturales y/o capacidades tecnoproductivas locales). Estas firmas muestran fuertes economías de especialización a escala global y, potencialmente, tienen mayores probabilidades de desarrollar procesos de upgrading. No obstante, la inserción en cadenas globales podría dificultar el 
avance hacia actividades de mayor complejidad y rentabilidad llevadas a cabo por las transnacionales.

3) Trama nacional para el mercado interno. Se trata de empresas cuyos proveedores de insumos y componentes son en su mayoría nacionales y cuyas ventas están destinadas principalmente al mercado doméstico. Al no participar en redes globales de producción, estas firmas tendrían un menor potencial para beneficiarse de nuevas tecnologías y, además, estarían sujetas a menores presiones competitivas para lograr progresos técnicos en comparación con las que participan en mercados internacionales.

4) Trama nacional exportadora. Como el caso anterior, se trata de compañías especializadas sobre una base nacional, pero se distinguen por una inserción exportadora dinámica. Su mayor competitividad internacional puede deberse a una más profunda inserción en los sistemas nacionales de innovación o a un aprovechamiento de las oportunidades de aprendizaje por interacción con compradores globales.

\section{b) Factores determinantes de las trayectorias de innovación: estimación de un modelo de respuestas múltiple}

Finalmente, se realizó un análisis econométrico para evaluar cómo incide la forma de inserción en las tramas productivas (y otros factores considerados) sobre las probabilidades de las pymes para emprender cada una de las trayectorias de innovación identificadas en el análisis de conglomerado. Para calcular estas probabilidades se recurrió a la estimación de un modelo logístico multinomial (MNL, por sus siglas en inglés), el cual consiste en una extensión del modelo logístico binario a un caso en el que la variable dependiente toma más de dos resultados posibles sin un orden determinado (Long, 1997).

Sea Tray ${ }_{i}$ la variable que indica cada una de las cuatro trayectorias de innovación posibles (según el análisis de conglomerado). De acuerdo al modelo MNL, la probabilidad de que la empresa adopte una cierta trayectoria viene dada por:

$$
\left.\operatorname{Prob}\left(\operatorname{Tray}_{i}=j\right) /\left(I_{i},\right) X_{i}\right)=\frac{\exp \left(\beta^{j} I_{i}+\gamma^{j} X_{i}\right)}{1+\sum_{j} \exp \left(\beta^{j} I_{i}+\gamma^{j} X_{i}\right)} ; j=1,2,3,4,
$$

donde $I_{i}$ y $X_{i}$ son las variables explicativas del modelo y $\beta^{j}$ y $\gamma^{j}$ sus coeficientes asociados. ${ }^{8}$ La identificación del modelo exige tomar un resultado base. En este

\footnotetext{
${ }^{8}$ Nótese que los valores de los coeficientes difieren según cada resultado.
} 
caso, se toma como resultado base del modelo $(j=0)$ la no realización de ninguna actividad de innovación. ${ }^{9}$

La variable $I_{i}$ recoge las cuatro formas de inserción de la empresa, según la tipología propuesta anteriormente. Además, se introduce una serie de factores de control (englobados en el vector $X_{i}$ ) que pueden afectar la probabilidad de que la firma siga algunas de las trayectorias posibles de innovación. Entre estos factores se incluyen variables habituales contempladas en la literatura sobre innovación, como el tamaño y la antigüedad de la empresa, el acceso al financiamiento externo y la proporción de empleo calificado respecto al total como medida indirecta de la capacidad de absorción (Cohen y Levinthal, 1990). Debido a la importancia de las interacciones con otros organismos para el proceso de innovación (Lundvall, 1992; Yoguel, Borello y Erbes, 2009), también sirven de control los vínculos de las empresas con otras instituciones (como universidades, agencias de desarrollo y centros tecnológicos). ${ }^{10}$ Asimismo se agregan variables dummy para controlar mediante la ubicación regional de la empresa. Por último, lo mismo se aplica a la trayectoria tecnológica sectorial. Siguiendo la clasificación de Pavitt (1984), se distingue entre sectores dominados por proveedores (industrias manufactureras tradicionales como las de textiles, vestimentas, calzados y cueros), intensivos en escala (industrias de proceso, como las de metales, química básica y caucho, y ensambladoras, como la de vehículos y la de bienes de consumo electrónicos), de proveedores especializados (productores de maquinarias, equipos e instrumentos) y basados en la ciencia (productores de químicos y de instrumentos médicos de precisión). De acuerdo con Pietrobelli y Rabellotti (2004), se modificó parcialmente la clasificación original distinguiendo los sectores intensivos en recursos naturales (industria alimentaria, maderera, minera). Esto responde a la particularidad de las economías latinoamericanas, en las que las ramas ligadas al procesamiento de materias primas tienen un gran peso.

La estimación del modelo MNL brinda información sobre dos cuestiones. En primer lugar, permite conocer en qué medida la probabilidad de llevar a cabo actividades internas de innovación se relaciona con la forma de inserción de las pymes en la cadena de valor. Esta información complementa la evidencia del conjunto de trabajos que analizan los vínculos entre la innovación y la inserción en el comercio internacional. En segundo lugar, permite evaluar si dichos vínculos, en caso que existan, son homogéneos respecto a los tipos de innovación o si,

\footnotetext{
${ }^{9}$ La probabilidad del caso base es: $\quad \operatorname{Prob}\left(\operatorname{Tray}_{i}=0 / I_{i}, X_{i}\right)=\frac{1}{1+\sum_{j} \exp \left(\beta^{j} I_{i}+\gamma^{j} X_{i}\right)} j=1,2,3,4$.

${ }^{10}$ Ver el cuadro A2 del anexo para una descripción de cada una de las variables de control.
} 
por el contrario, existen distintos grados de asociación entre la forma de inserción en tramas productivas y ciertas trayectorias innovativas.

Al ser una muestra de datos transversal, la estimación no permite interpretar los vínculos como relaciones de causalidad. Dos cuestiones merecen ser señaladas al respecto. Primero, este problema puede mitigarse parcialmente usando como control las características de las empresas que pueden explicar tanto la inserción productiva internacional como las actividades de innovación de manera tal que se reduzca la heterogeneidad no observable (Almeida y Fernandes, 2008). En este sentido, las variables de control incorporadas al modelo pueden correlacionarse tanto con la forma de inserción como con la realización de actividades de innovación. En segundo lugar, aun reconociendo los problemas de endogeneidad entre las variables de interés y la imposibilidad de inferir efectos de causalidad, la información sobre asociaciones estadísticamente significativas y su magnitud no deja de ser un aporte para hallar evidencia sobre los patrones de innovación de las empresas que se insertan en la economía internacional. En caso de contar con datos longitudinales o variables instrumentales pertinentes, se podrá avanzar en el control de la endogeneidad debida a la simultaneidad en las variables.

\section{RESULTADOS}

\section{Distinción de patrones de innovación en las pymes argentinas}

Basados en la información del MAPAPYME, se consideran nueve variables, cada una referida a un tipo de actividad de innovación: tecnología de producto, tecnología de proceso, diseño, calidad, organización, capacitación, comercialización e investigación y desarrollo de producto. En todos los casos, son dicotómicas: indican si la firma ha realizado o no cada actividad en cuestión entre 2005 y 2006. Del total de 2486 empresas, el ACP se efectuó en las 1187 empresas que reportaron haber realizado al menos una de las actividades de innovación señaladas.

En el cuadro 1 se muestra la matriz factorial ${ }^{11}$ con los coeficientes de correlación de cada componente con cada variable original. ${ }^{12}$ En la última columna del cuadro aparece la varianza de cada variable que no es explicada por el

${ }^{11}$ Como las variables son binarias, se trabaja con la matriz tetratórica de correlaciones (Battisti y Stoneman, 2010). El estadístico de Kaiser-Meyer-Olkin, que brinda informaron sobre la adecuación de los datos para realizar un $\mathrm{ACP}$, posee un valor de 0.770 .

${ }^{12}$ La elección del número de componentes fue realizada con el criterio de Kaiser o regla de Kaiser-Guttman: se mantuvieron los tres componentes con autovalores superiores a uno. 
conjunto de los componentes. A fin de posibilitar la interpretación de la información resumida en la matriz factorial se presenta un diagrama radial (cuadro 2) con los coeficientes de correlación.

Cuadro 1. Análisis de componentes principales de las actividades de innovación: matriz factorial

\begin{tabular}{l|cccc}
\hline \multicolumn{1}{c|}{ Variable } & Componente 1 & Componente 2 & Componente 3 & $\begin{array}{c}\text { Varianza no } \\
\text { explicada }\end{array}$ \\
\hline Comercialización & -0.173 & 0.218 & 0.613 & 0.256 \\
Organización del trabajo & 0.042 & -0.146 & 0.635 & 0.298 \\
$\begin{array}{l}\text { Capacitación de recursos } \\
\text { humanos }\end{array}$ & 0.406 & -0.356 & 0.302 & 0.407 \\
Calidad & 0.372 & 0.030 & 0.193 & 0.451 \\
Tecnología de producto & 0.533 & 0.174 & -0.178 & 0.000 \\
Tecnología de proceso & 0.594 & -0.016 & -0.085 & 0.254 \\
Investigación & 0.148 & 0.357 & 0.223 & 0.355 \\
Diseño & 0.079 & 0.526 & -0.038 & 0.391 \\
Desarrollo de producto & 0.000 & 0.607 & 0.051 & 0.243 \\
\hline $\begin{array}{l}\text { Proporción de la varianza } \\
\text { explicada por el componente }\end{array}$ & 0.263 & 0.215 & 0.202 & \\
\hline
\end{tabular}

Nota: Método de rotación: quartimax. Número de observaciones = 1187.

Fuente: Elaboración propia con datos de MAPAPYME.

Cuadro 2. Nivel de las cargas factoriales asociados a cada variable

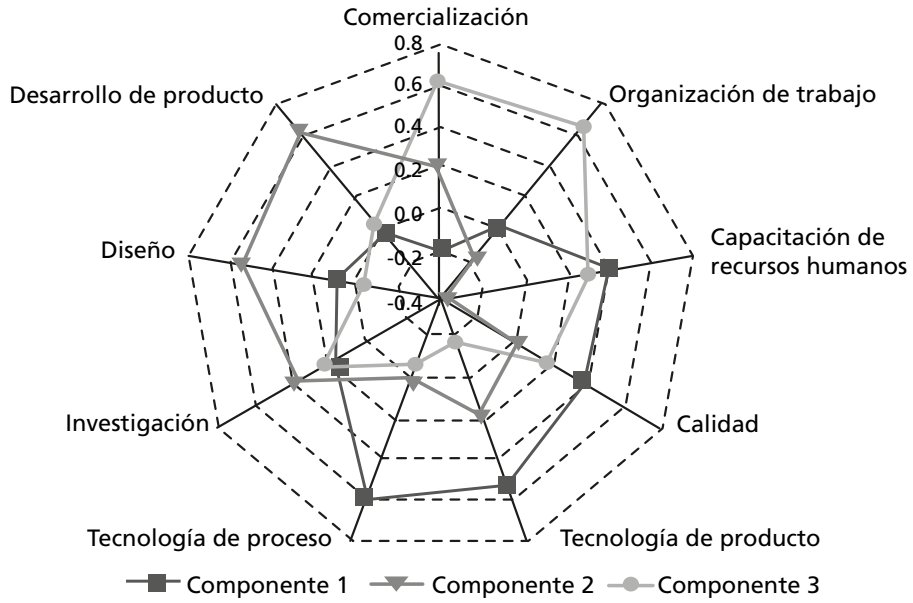

Fuente: Elaboración propia con datos de MAPAPYME. 
La interpretación de los componentes es crucial. Cada componente resume un grupo de actividades innovadoras que identifica, así, diferentes patrones de actividades de innovación de las pymes. De acuerdo a los coeficientes de correlación, se propone la siguiente identificación de cada componente:

1) Patrón de actividades de innovación para mejoras tecnológicas de proceso y producto. Este componente abarca principalmente actividades destinadas a mejoras tecnológicas en productos y procesos. En menor medida, se asocia también con la calidad y la capacitación del personal. Destaca, además, su nula relación con actividades de comercialización y la muy baja relación con actividades de diseño y de desarrollo de productos. De esta manera, este patrón se interpreta como actividades de innovación destinadas a mejorar los procesos de producción y la calidad de los bienes, y se relaciona con el aprendizaje por experiencia (learning by doing) en la producción.

2) Patrón de actividades de ID y diseño. Este componente muestra valores altos, sobre todo, para las variables de diseño y de desarrollo de productos. También tiene una alta correlación con la investigación. Este componente involucraría, a diferencia del anterior, actividades de innovación en torno a la comercialización de los productos, pero se asocia negativamente con nuevos métodos de capacitación de los empleados. Con base en estos resultados, se entiende que este componente representa un patrón orientado a la realización de actividades de innovación de productos, entendida como la introducción de un nuevo (o mejorado) producto al mercado. Las tareas de investigación permiten adquirir conocimientos que orienten las innovaciones específicas en producto. Se vincula, a su vez, con la comercialización, ya que el lanzamiento de un producto al mercado puede exigir nuevas estrategias de venta. ${ }^{13}$

3) Patrón de actividades de innovaciones no tecnológicas. Este componente se destaca por los altos valores de las variables organización del trabajo y comercialización. Además, estaría acompañado, aunque en menor medida, por tareas de innovaciones en capacitación. En materia de organización del trabajo, puede implicar la introducción de nuevos métodos en las prácticas de

${ }^{13}$ Debe tenerse en cuenta que se trata de ID y de actividades de diseño de carácter adaptativo y no de esfuerzos destinados a innovaciones de frontera. Dado que se están considerando pymes de los países en desarrollo, sus búsquedas están dirigidas a la introducción de procesos y productos ya conocidos en el mundo, pero que son nuevos para ellas o, quizás, novedosos en el mercado local o regional. 
la empresa (para organizar las rutinas o los procedimientos de gestión de los trabajos) y en las relaciones exteriores (con otras empresas o instituciones públicas).

En síntesis, el ACP permite resumir las actividades de innovación en tres patrones diferentes: por un lado, el referido a innovaciones no tecnológicas (organizacionales y comerciales) y, por otro, el destinado a innovaciones tecnológicas, que se subdivide, a su vez, en innovaciones en ID y diseño de productos, y en actividades destinadas al aprendizaje tecnológico de carácter acumulativo. ${ }^{14}$ Esta subdivisión permite diferenciar el desarrollo de competencias relacionadas con mejoras en el proceso productivo y en la calidad de los productos (aprendizaje acumulativo) de las vinculadas a ID y diseño de nuevos productos.

\section{Trayectorias de innovación: agrupamiento de las pymes según los patrones de actividades de innovación}

Con los resultados obtenidos mediante el $\mathrm{ACP}$, las pymes fueron agrupadas de acuerdo a la puntuación de cada empresa en cada componente o patrón de innovación. De acuerdo a esto, se obtienen cuatro grupos de empresas. ${ }^{15}$

Para analizar el tipo de actividades de innovación de cada uno de estos grupos, se presenta un diagrama radial (cuadro 3 ) que muestra el grado de intensidad promedio de cada patrón de actividades en las empresas de cada grupo. Teniendo en cuenta que el promedio de cada patrón para el total de pymes con al menos una actividad de innovación es cero, puede inferirse qué patrón de actividades prevalece en cada grupo.

De acuerdo a los valores promedio de los patrones en cada conglomerado, se concluye que el grupo 1 (495 empresas) reúne aquellas firmas que se concentran en la realización de actividades destinadas a innovaciones no tecnológicas (organización y comercialización). En el grupo 2 (154 empresas) aparecen aquellas que se distinguen por un patrón orientado preponderantemente hacia innova-

${ }^{14}$ La división del rango total de innovaciones se asemeja a la de Battisti y Stoneman (2010), quienes, también a través de un análisis factorial, dividen las actividades en organizacionales y tecnológicas, con la novedad de que en el presente trabajo, las tecnológicas se subdividen en dos dimensiones.

${ }^{15}$ La elección del número de grupos se basó en los criterios de Calinski y Harabasz y de DudaHart. Ambos indican que el mayor grado de distinción entre grupos se obtiene por medio de cuatro agrupamientos. 
24 ECONOMÍA: TEORÍA Y PRÁCTICA • Nueva Época, número 45, julio-diciembre 2016

ciones en mejoras de la tecnología de proceso y de productos. Por su parte, el grupo 3 (291 empresas) se destaca sólo por el patrón que incluye actividades de investigación y desarrollo y diseño de productos. Finalmente, el grupo 4 (257 empresas) está formado por compañías que se caracterizan por tener la mayor intensidad en actividades de innovación abarcando, a la vez, los tres patrones.

Cuadro 3. Intensidad promedio de cada patrón de innovación por grupo de empresas

Mejoras tecnológicas de producto y de proceso

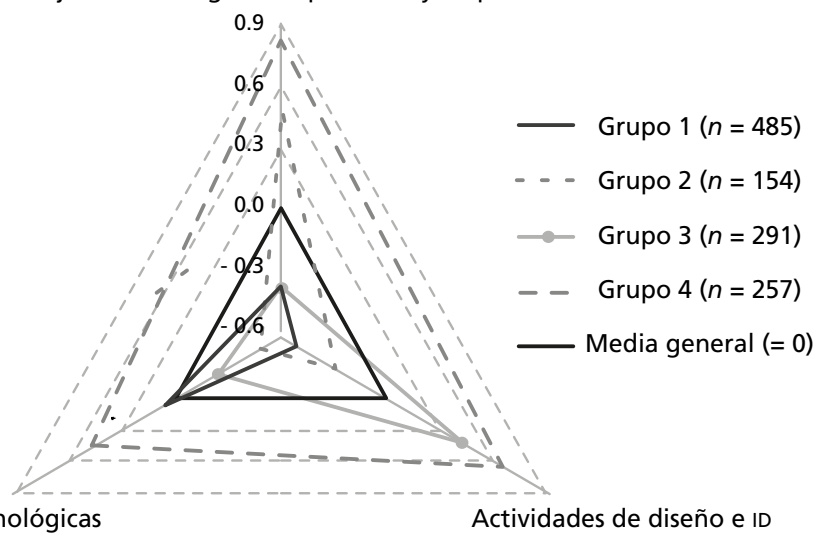

Actividades no tecnológicas

Actividades de diseño e ID

Nota: Cálculos sobre el total de empresas con al menos una actividad de innovación ( $n=1$ 187)

Fuente: Elaboración propia con datos de MAPAPYME.

Cuadro 4. Trayectorias de innovación de las pymes

\begin{tabular}{|c|c|c|}
\hline $\begin{array}{l}\text { Tipo de } \\
\text { trayectoria }\end{array}$ & $\begin{array}{l}\text { Cantidad de } \\
\text { empresas }\end{array}$ & $\begin{array}{l}\text { Patrones de innovación predominantes } \\
\text { en cada trayectoria }\end{array}$ \\
\hline Trayectoria 0 & 1299 & Sin actividades de innovación \\
\hline Trayectoria 1 & 485 & Patrón orientado a innovaciones no tecnológicas \\
\hline Trayectoria 2 & 154 & $\begin{array}{l}\text { Patrón orientado a innovaciones en mejoras } \\
\text { tecnológicas de proceso y de producto }\end{array}$ \\
\hline Trayectoria 3 & 291 & Patrón orientado a innovaciones de ID y diseño \\
\hline Trayectoria 4 & 257 & $\begin{array}{l}\text { Desarrollo conjunto de los patrones de innovaciones no } \\
\text { tecnológicas, de mejoras de proceso y producto, y de } \\
\text { ID y diseño }\end{array}$ \\
\hline Total de empresas & 2486 & \\
\hline
\end{tabular}

Fuente: Elaboración propia con datos de MAPAPYME. 
Cada uno de estos cuatro grupos representa, entonces, una trayectoria de innovación que se distingue por el tipo de patrón de actividades seguido por las empresas. Si se considera, además, a las que no realizan ninguna actividad de innovación (1 299 empresas), se obtiene en total cinco trayectorias de innovación (cuadro 4).

\section{Inserción en tramas productivas}

La propuesta de tipología de formas de inserción se implementó a partir de la información disponible sobre la localización de los clientes y los proveedores de las pymes. En relación al modo de articulación con sus clientes, se diferenció entre empresas exportadoras y no exportadoras. El criterio utilizado para esta discriminación consistió en denominar "exportadoras" a aquellas cuyo porcentaje de ventas externas respecto a las totales es superior a la media del total de pymes manufactureras de la muestra (5.7\%). Análogamente, fueron catalogadas como "importadoras" aquellas cuya proporción de insumos y componentes importados es superior al promedio de la muestra $(4.9 \%) .{ }^{16}$

Cuadro 5. Tipología según la forma de inserción en la cadena de valor

\begin{tabular}{|c|c|c|c|c|c|c|}
\hline \multicolumn{2}{|c|}{$\begin{array}{l}\text { Origen de los insumos y } \\
\text { componentes }\end{array}$} & \multicolumn{2}{|c|}{$\begin{array}{l}\text { Destino de la } \\
\text { producción }\end{array}$} & \multirow[t]{2}{*}{$\begin{array}{c}\text { Forma de inserción } \\
\text { en tramas } \\
\text { productivas }\end{array}$} & \multicolumn{2}{|c|}{$\begin{array}{l}\text { Cantidad de } \\
\text { empresas }\end{array}$} \\
\hline & $\begin{array}{l}\text { Coeficiente } \\
\text { de } \\
\text { importación }\end{array}$ & & $\begin{array}{l}\text { Coeficiente } \\
\text { de } \\
\text { exportación }\end{array}$ & & Número & Porcentaje \\
\hline $\begin{array}{l}\text { Mercado } \\
\text { externo }\end{array}$ & $>4.9 \%$ & $\begin{array}{l}\text { Mercado } \\
\text { externo }\end{array}$ & $>5.7 \%$ & $\begin{array}{c}\text { Cadena de valor } \\
\text { global }\end{array}$ & 163 & 6.6 \\
\hline $\begin{array}{l}\text { Mercado } \\
\text { nacional }\end{array}$ & $<4.9 \%$ & $\begin{array}{l}\text { Mercado } \\
\text { externo }\end{array}$ & $>5.7 \%$ & $\begin{array}{l}\text { Trama nacional } \\
\text { exportadora }\end{array}$ & 240 & 9.7 \\
\hline $\begin{array}{l}\text { Mercado } \\
\text { externo }\end{array}$ & $>4.9 \%$ & $\begin{array}{l}\text { Mercado } \\
\text { nacional }\end{array}$ & $<5.7 \%$ & $\begin{array}{l}\text { Ensamble para el } \\
\text { mercado interno }\end{array}$ & 225 & 9.1 \\
\hline $\begin{array}{l}\text { Mercado } \\
\text { nacional }\end{array}$ & $<4.9 \%$ & $\begin{array}{l}\text { Mercado } \\
\text { nacional }\end{array}$ & $<5.7 \%$ & $\begin{array}{l}\text { Trama nacional para } \\
\text { el mercado interno }\end{array}$ & 1858 & 7.7 \\
\hline Total & & & & & 2486 & 100 \\
\hline
\end{tabular}

Fuente: Elaboración propia con datos de MAPAPYME.

\footnotetext{
${ }^{16}$ Ambos coeficientes medios se calcularon para el total de empresas de la muestra (2 486).
} 
La conjunción de las aperturas según el destino de la producción y el origen de los insumos genera cuatro combinaciones posibles (cuadro 5). No se trata de una tipología definitiva, ya que es posible que las empresas muten sus estrategias y reconfiguren sus articulaciones productivas ante cambios en el contexto competitivo y macroeconómico.

\section{Efectos de la inserción en CVG sobre las trayectorias de innovación: estimación de un modelo de respuestas múltiples}

Con los indicadores construidos en la sección previa, se procedió a estimar el modelo MNL propuesto previamente. Los resultados completos de la estimación se muestran en el cuadro 6.

Respecto a la significación estadística ${ }^{17}$ del efecto que cada forma de inserción tiene sobre las probabilidades de que la firma siga alguna de las trayectorias propuestas (respecto a la no realización de actividades innovadoras), los resultados muestran que las tres formas de inserción que implican vínculos con la economía global (ensamble para el mercado interno, trama exportadora y CVG) se relacionan positivamente con la probabilidad de que la empresa adopte los tres patrones de innovación conjuntamente (trayectoria 4). Asimismo, la inserción en CVG también se relaciona positivamente con la probabilidad de que la pyme se concentre exclusivamente en un patrón de actividades orientado hacia mejoras tecnológicas progresivas (trayectoria 2).

\section{Cuadro 6. Resultados del modelo logístico multinomial (continúa)}

\begin{tabular}{|c|c|c|c|c|}
\hline & $\begin{array}{c}\text { Trayectoria } 1 \\
\text { Innovaciones no } \\
\text { tecnológicas }\end{array}$ & $\begin{array}{c}\text { Trayectoria } 2 \\
\text { Mejoras de } \\
\text { proceso y } \\
\text { de producto } \\
\end{array}$ & $\begin{array}{c}\text { Trayectoria } 3 \\
\text { Diseño y } \\
\text { desarrollo } \\
\text { de productos }\end{array}$ & $\begin{array}{l}\text { Trayectoria } 4 \\
\text { Desarrollo } \\
\text { conjunto de los } \\
\text { tres patrones }\end{array}$ \\
\hline & Coeficiente & Coeficiente & Coeficiente & Coeficiente \\
\hline $\begin{array}{l}\text { Tamaño (logaritmo } \\
\text { del número de } \\
\text { empleados) }\end{array}$ & $0.258^{*}$ & $0.586^{*}$ & 0.137 & $0.591 *$ \\
\hline Edad (años) & -0.004 & $-0.014 * *$ & -0.006 & -0.006 \\
\hline Vinculada & 0.027 & 0.384 & -0.267 & -0.337 \\
\hline
\end{tabular}

${ }^{17}$ En adelante se considerará que una variable es estadísticamente significativa cuando puede rechazarse la hipótesis nula de que su coeficiente asociado es cero con una significación de $10 \%$. 
Cuadro 6. Resultados del modelo logístico multinomial (concluye)

\begin{tabular}{|c|c|c|c|c|}
\hline $\begin{array}{l}\text { Participación } \\
\text { extranjera }\end{array}$ & 0.200 & 0.247 & -0.052 & 0.153 \\
\hline Financiamiento & $0.623 *$ & 0.294 & $0.546^{*}$ & $0.709 *$ \\
\hline \multicolumn{5}{|l|}{ Sector a } \\
\hline $\begin{array}{l}\text { Intensivas } \\
\text { en recursos } \\
\text { naturales }\end{array}$ & 0.205 & -0.079 & 0.029 & $-0.500 * *$ \\
\hline $\begin{array}{l}\text { Intensivas en } \\
\text { escala }\end{array}$ & -0.037 & 0.370 & -0.229 & 0.342 \\
\hline $\begin{array}{l}\text { Proveedores } \\
\text { especializados }\end{array}$ & 0.060 & 0.521 & $0.520 * *$ & 0.286 \\
\hline $\begin{array}{l}\text { Basadas en la } \\
\text { ciencia }\end{array}$ & -0.033 & -0.659 & 0.334 & $0.972 * * *$ \\
\hline $\begin{array}{l}\text { Capacidad de } \\
\text { absorción }\end{array}$ & $1.408 * *$ & 1.066 & $1.885^{* *}$ & $2.777^{*}$ \\
\hline \multicolumn{5}{|l|}{ Vínculos } \\
\hline $\begin{array}{l}\text { Organismo } \\
\text { público }\end{array}$ & $0.324 * *$ & $0.409 * *$ & 0.053 & $0.713^{*}$ \\
\hline $\begin{array}{l}\text { Cámara } \\
\text { empresarial }\end{array}$ & $0.464^{*}$ & 0.150 & 0.312 & 0.097 \\
\hline Universidad & 0.073 & -0.125 & 0.374 & $0.685^{*}$ \\
\hline $\begin{array}{l}\text { Consultor } \\
\text { externo }\end{array}$ & $0.848^{*}$ & $1.090 *$ & $1.089 *$ & $1.371 *$ \\
\hline $\begin{array}{l}\text { Centro } \\
\text { tecnológico }\end{array}$ & $-0.819 * * *$ & 0.154 & 0.239 & 0.374 \\
\hline $\begin{array}{l}\text { Agencia de } \\
\text { desarrollo }\end{array}$ & 0.650 & 0.758 & -0.096 & 0.718 \\
\hline \multicolumn{5}{|l|}{ Forma de inserción } \\
\hline Ensamble & 0.384 & 0.379 & 0.247 & $0.690 * *$ \\
\hline $\begin{array}{l}\text { Trama } \\
\text { exportadora }\end{array}$ & 0.170 & 0.017 & 0.339 & $0.605^{* *}$ \\
\hline CVG & 0.051 & $1.123^{*}$ & 0.223 & $1.077^{*}$ \\
\hline
\end{tabular}

Observaciones: 2486

Logaritmo de la función de verosimilitud $=2541.574$

Pseudo $R^{2}=0.2231$ $\operatorname{LR} X^{2}(232)=1460.01$ Probabilidad $>X^{2}=0.0000$

a Los principales resultados son robustos si se controla mediante el sector industrial a dos dígitos de la Clasificación Internacional Industrial Uniforme (CIIU) en lugar de la clasificación sectorial de Pavitt (1984).

Nota: *, **, *** implican significación a 1\%, 5\% y $10 \%$ respectivamente. La estimación incluye dummies para controlar por la ubicación regional de la empresa.

Fuente: Elaboración propia con datos de MAPAPYME. 
Estos resultados indican, en primer lugar, que las trayectorias de actividades que se concentran exclusivamente en el desarrollo y diseño de productos o exclusivamente en actividades no tecnológicas (trayectorias 1 y 3 , respectivamente), no se asocian con el grado de integración a la economía mundial; al menos, cuando otras características, tales como tamaño, sector, antigüedad, etcétera, se usan como variables de control. En segundo lugar, la posibilidad de que la pyme emprenda una trayectoria de innovación con los tres patrones de actividades (trayectoria 4) crece cuando la empresa pasa del mercado doméstico a una inserción en el ensamble para el mercado doméstico, en una trama exportadora o en una CVG. En tercer lugar, la inserción en CVG posee además un impacto positivo sobre la probabilidad de que la empresa dedique sus actividades exclusivamente a innovaciones orientadas a mejoras en los procesos de producción y en la calidad de los productos, con escasos o nulos esfuerzos en ID y diseño de nuevos productos y en actividades de organización y comercialización (trayectoria 2).

A fin de profundizar la interpretación de los resultados del modelo, la gráfica 1 muestra cómo cambian las probabilidades estimadas de cada trayectoria cuando la firma pasa de insertarse en una cadena de valor doméstica a una trama exportadora, al ensamble para el mercado interno o una CVG. Como las predicciones de los modelos no lineales dependen de los valores que tomen las variables independientes, se fijan los valores de las variables de control. ${ }^{18} \mathrm{El}$ eje de las abscisas mide la variación en la probabilidad predicha (en puntos porcentuales) de cada resultado, mientras que el de las ordenadas distingue las formas de inserción contempladas en el análisis. ${ }^{19}$

Esta gráfica permite constatar que si la pyme pasa de una cadena doméstica a una CVG, la probabilidad de seguir la trayectoria centrada en innovaciones progresivas en proceso y producto (trayectoria 2 ) aumenta $6.4 \%$, mientras que la probabilidad de seguir los tres patrones conjuntamente (trayectoria 4) aumenta $7.5 \%$. Por otro lado, la inserción en una trama exportadora y en el ensamble para el mercado interno poseen un efecto significativo exclusivamente para la trayectoria 4. Puede observarse que en ambos casos los efectos son similares (aproximadamente $3.7 \%$ ), pero menores que el efecto de la inserción en una CVG.

${ }^{18}$ El tamaño, la proporción de empleo calificado y la antigüedad de la empresa se fijan en sus valores medianos: $0.034,3.5 \%$ y 14 años, respectivamente. Además, se considera que la firma no tiene vínculos y que su capital es 100\% nacional. Los valores del resto de las variables -ubicación regional, acceso al financiamiento, sector de actividad, según la clasificación de Pavitt (1984)- se toman de los observados en la muestra.

${ }^{19}$ La gráfica sólo presenta los efectos de las variables con significación estadística mayor a $10 \%$. 
Las variaciones en las probabilidades confirman los resultados señalados anteriormente. La inserción en CVG no sólo aumenta la probabilidad de que la empresa desarrolle los tres patrones conjuntamente, sino que, además, crece la probabilidad de que realice actividades exclusivamente destinadas a mejoras tecnológicas de producto y proceso sin el desarrollo de actividades de ID y diseño, ni innovaciones en las formas de comercialización. De esta manera, la inserción en CVG se vincularía con dos posibles trayectorias de innovación.

Gráfica 1. Variaciones en la probabilidad estimada ante cambios en la forma de inserción

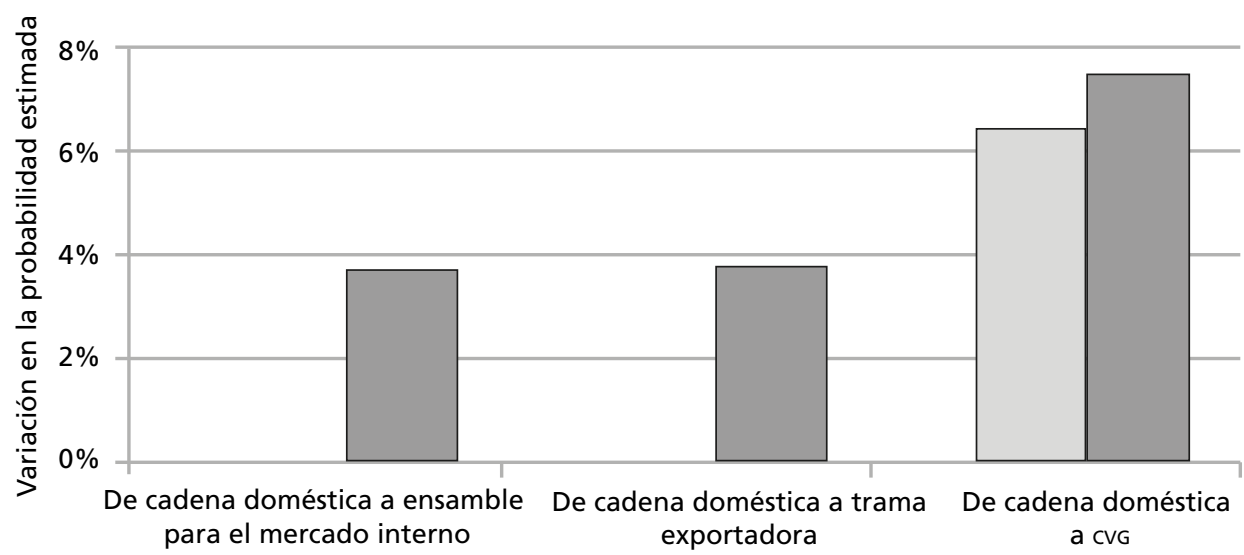

Trayectoria 2 - Patrón de innovaciones en mejoras de proceso y producto

Trayectoria 4 - Desarrollo conjunto de los tres patrones

Fuente: Elaboración propia con datos de MAPAPYME.

Si bien el objetivo primario de este trabajo consistió en analizar en qué medida la forma de inserción de las pymes en la cadena de valor influye en el desarrollo de distintos patrones de actividades de innovación, la incorporación de variables adicionales en el modelo permitió conocer cómo impactan otros factores en cada trayectoria de innovación (cuadro 7). A modo de síntesis, se puede decir que los resultados obtenidos son los siguientes:

- La trayectoria de actividades centradas en innovaciones no tecnológicas (o con escasas innovaciones tecnológicas) no se asocia a la inserción en la economía global y es característica de los sectores intensivos en recursos naturales. El progreso técnico, por lo tanto, vendría de la compra de 
insumos y equipos de las industrias proveedoras. Este perfil de innovación, a su vez, dependería de la posibilidad de acceder al crédito externo y del tamaño de la empresa. Los vínculos claves serían los que se establecen con consultores externos, organismos públicos y cámaras empresariales. La importancia de estas últimas es exclusiva de este tipo de actividades de innovación.

- La integración en CVG impacta positivamente en la adopción de una trayectoria orientada a innovaciones en mejoras tecnológicas de proceso y producto (con escasas actividades de ID y diseño). Es la trayectoria predominante entre las industrias intensivas en escala y, en menor medida, entre algunas proveedoras de bienes de capital. La probabilidad de seguirla dependería de los vínculos con consultores externos y organismos públicos. A diferencia de las otras trayectorias, no dependería del acceso al financiamiento externo, de lo que puede deducirse la mayor importancia de las fuentes de financiamiento propias para solventar el tipo de esfuerzos innovadores de esta trayectoria. También se destaca por ser la única que no se asocia con las capacidades de absorción. Por último, el tamaño es igualmente una variable relevante para esta trayectoria.

Cuadro 7. Resumen de efectos sobre las trayectorias de innovación de las pymes

\begin{tabular}{|c|c|c|c|c|}
\hline \multicolumn{5}{|c|}{ Patrones de innovación } \\
\hline Determinantes & $\begin{array}{c}\text { Innovaciones no } \\
\text { tecnológicas } \\
\text { (trayectoria 1) }\end{array}$ & $\begin{array}{c}\text { Mejoras de } \\
\text { proceso y de } \\
\text { producto } \\
\text { ( trayectoria 2) }\end{array}$ & $\begin{array}{c}\text { Diseño y } \\
\text { desarrollo de } \\
\text { productos } \\
\text { ( trayectoria 3) }\end{array}$ & $\begin{array}{c}\text { Desarrollo } \\
\text { conjunto de los } \\
\text { tres patrones } \\
\text { ( trayectoria 4) }\end{array}$ \\
\hline Tamaño & SI & SI & - & SI \\
\hline $\begin{array}{l}\text { Formas de } \\
\text { inserción en la } \\
\text { cadena de valor }\end{array}$ & - & CVG & - & $\begin{array}{c}\text { CVG, ensamble, } \\
\text { trama } \\
\text { exportadora }\end{array}$ \\
\hline $\begin{array}{l}\text { Capacidad de } \\
\text { absorción }\end{array}$ & SI & - & SI & SI \\
\hline $\begin{array}{c}\text { Sectores } \\
\text { característicos }\end{array}$ & $\begin{array}{l}\text { Intensivos en } \\
\text { recursos naturales }\end{array}$ & $\begin{array}{l}\text { Intensivos en } \\
\text { escala }\end{array}$ & $\begin{array}{l}\text { Proveedores } \\
\text { especializados }\end{array}$ & $\begin{array}{c}\text { Con base en la } \\
\text { ciencia }\end{array}$ \\
\hline $\begin{array}{c}\text { Financiamiento } \\
\text { externo }\end{array}$ & SI & - & SI & SI \\
\hline $\begin{array}{l}\text { Instituciones } \\
\text { relevantes }\end{array}$ & $\begin{array}{c}\text { Organismo } \\
\text { público, cámara } \\
\text { empresarial, } \\
\text { consultor externo }\end{array}$ & $\begin{array}{c}\text { Organismo } \\
\text { público, consultor } \\
\text { externo }\end{array}$ & $\begin{array}{l}\text { Consultor } \\
\text { externo }\end{array}$ & $\begin{array}{c}\text { Organismo } \\
\text { público, consultor } \\
\text { externo, } \\
\text { universidad }\end{array}$ \\
\hline
\end{tabular}

Nota: $\mathrm{SI}=$ impacto positivo y estadísticamente significativo.

Fuente: Elaboración propia con datos de MAPAPYME. 
- La probabilidad de que una empresa concentre sus actividades en un patrón de innovaciones orientadas al desarrollo y diseño de productos, con pocos esfuerzos en tecnología de proceso y en innovaciones organizacionales, no se relaciona con la forma de inserción en la cadena de valor. Esta trayectoria sobresale entre los proveedores especializados, sectores que se basan en capacidades de diseño para la adaptación y mejora de productos en función de los requisitos específicos de los usuarios. A diferencia del resto, esta trayectoria no depende del tamaño de la empresa, lo que indicaría una mayor presencia de empresas pequeñas. En cambio, sí es importante el acceso al financiamiento externo. Entre los vínculos, sólo serían relevantes los consultores externos.

- Finalmente, la probabilidad de que la empresa siga conjuntamente los tres patrones de innovación, es decir, que tenga un conjunto de actividades de innovación balanceado y completo, sería fundamentalmente una característica de los sectores basados en la ciencia. El tamaño y el financiamiento externo impactan positivamente en la probabilidad de que estas pymes sigan tal trayectoria. Además de los vínculos con consultores externos y organismos públicos, esta trayectoria depende de los vínculos con universidades, que no son relevantes en los casos anteriores. La integración en CVG tiene una influencia positiva sobre esta clase de actividades innovadoras, aunque no es un efecto exclusivo de esta forma de inserción, ya que también se observa en la inserción en tramas exportadoras y en el ensamble para el mercado interno.

\section{REFLEXIONES FINALES}

El presente trabajo se propone contribuir a la discusión sobre las posibilidades de upgrading de las pymes manufactureras argentinas que se integran a CVG. Los resultados han mostrado que algunas pueden desarrollar capacidades tecnoproductivas complejas sobre la base de esfuerzos innovadores en ID y diseño de productos. No obstante, estos resultados merecen que se hagan algunas consideraciones de matiz.

En primer lugar, la integración a una CVG no sería condición necesaria ni suficiente para una trayectoria virtuosa de actividades innovadoras. Por un lado, no sería suficiente porque los resultados muestran que la integración de las empresas a las CVG también se vincula con un desarrollo de capacidades concentradas exclusivamente en lograr mejoras tecnológicas de carácter progresivo, es 
decir, esfuerzos internos orientados a los procesos y la calidad del producto sin avanzar hacia otras actividades de mayor complejidad, como ID y diseño de nuevos productos.

En este marco, toda evaluación sobre las posibilidades de incrementar la competitividad del sector de pymes debería contemplar su modo de integración en los sistemas globales de producción. La importancia de que las empresas insertas en una CVG controlen las actividades de ID y diseño radica en que esto permite un salto cualitativo desde una especialización basada en ventajas comparativas estáticas hacia la creación de ventajas comparativas dinámicas que permitan incrementar el valor agregado de sus exportaciones y mejorar la inserción de las empresas en la economía mundial.

Por otro lado, la integración en CVG tampoco sería condición necesaria, ya que la trayectoria virtuosa que incluye todas las dimensiones de esfuerzos tecnológicos no es exclusiva de firmas insertas en tales cadenas. Esta trayectoria también se observa en las pymes que importan sus insumos y venden localmente su producción, así como en aquellas que exportan sobre una base de aprovisionamiento doméstico.

En segundo lugar, aun cuando la evidencia muestra que es posible que las empresas insertas en CVG emprendan procesos de upgrading, surge la pregunta sobre si estos procesos a nivel microeconómico son suficientes para avanzar en dinámicas de cambio estructural y diversificación productiva. Aun cuando cierta literatura ha remarcado que la mayor segmentación internacional de los procesos productivos ofrece oportunidades a los países periféricos para reducir la brecha tecnológica y mitigar los tradicionales problemas de heterogeneidad estructural (Memedovic, 2004; BID, 2014), la evidencia microeconómica recolectada en el presente trabajo no es suficiente para sostener la existencia de estas oportunidades, ya que una cuestión clave que no permite ver el tipo de análisis aquí presentado es la densidad o significación de los casos de integración virtuosa respecto a la totalidad del tejido productivo.

En ese sentido, asociar la evidencia empírica de procesos de upgrading en cadenas globales con las posibilidades del cambio estructural exige, al menos, un análisis que trascienda el comportamiento individual de cada firma e incorpore el despliegue de complementariedades y procesos de difusión de tecnología. Por consiguiente, se entiende que es necesario analizar en futuros trabajos si el desarrollo de capacidades por parte de empresas insertas en CVG posee un carácter localizado o si, en cambio, existen procesos de difusión de conocimiento y de articulación con el resto de la estructura productiva doméstica. 
En tercer y último lugar, se entiende que el análisis de la presente investigación y las conclusiones que de él se desprenden no están exentos de ciertas limitaciones. Por un lado, el análisis es de carácter estático, por lo que no considera la posibilidad de que las trayectorias de innovación de las empresas insertas en cadenas globales varíen con el tiempo. Los estudios de caso han resaltado que las formas de gobernanza dentro de las cadenas son evolutivas y que, por ende, las posibilidades de upgrading cambian.

Por otro lado, los resultados de la estimación del modelo econométrico se obtuvieron usando factores observables como variables de control, lo cual obliga a acotar su interpretación. Esto se debe a que existe el riesgo de omisión de variables no observables que afectan simultáneamente tanto la inserción internacional de las empresas como sus actividades de innovación. Si éste fuera el caso, los coeficientes analizados entre la forma de inserción y las trayectorias de patrones de innovación responderían al efecto de esta variable no observada. Tales problemas podrían mitigarse a través del uso de variables instrumentales o con datos en panel.

\section{ANEXo}

\section{Cuadro A1. Clasificación sectorial basada en Pavitt*}

\begin{tabular}{c|c}
\hline Clasificación sectorial & $\begin{array}{c}\text { Código de la Clasificación Internacional Industrial Uniforme } \\
\text { (rev. 3) (a tres dígitos, excepto la rama 242 - Fabricación de } \\
\text { otros productos químicos) }\end{array}$ \\
\hline $\begin{array}{c}\text { Intensivos en recursos } \\
\text { naturales }\end{array}$ & $\begin{array}{l}151,152,153,154,155,158,201,202,210,231,232,233, \\
272,361,369\end{array}$ \\
\hline $\begin{array}{c}\text { Dominados por } \\
\text { proveedores }\end{array}$ & $\begin{array}{l}171,172,173,181,182,184,189,191,192,221,222,223,251, \\
252,281,289,372\end{array}$ \\
\hline Intensivos en escala & $\begin{array}{l}241,243,244,261,269,271,273,293,314,315,323,333,334, \\
341,342,343,359,242.2,242.4,242.9\end{array}$ \\
\hline Proveedores & $291,292,300,311,312,313,319,351,352$ \\
\hline especializados & $321,322,331,332,353,242.1,242.3$ \\
\hline Basados en la ciencia &
\end{tabular}

* La agrupación de los sectores industriales según sus trayectorias de progreso técnico obedece a la clasificación propuesta por Pavitt (1984) y modificada por Pietrobelli y Rabellotti (2004). 
34 ECONOMÍA: TEORÍA Y PRÁCTICA • Nueva Época, número 45, julio-diciembre 2016

\section{Cuadro A2. Indicadores utilizados en el modelo multinomial}

\begin{tabular}{|c|c|}
\hline Variable & Descripción \\
\hline Tamaño & Número de empleados de la empresa en 2006. \\
\hline Edad & Años de antigüedad de la empresa en 2006. \\
\hline Vinculación & Si la empresa se encuentra o no vinculada con otra empresa. \\
\hline Participación extranjera & $\begin{array}{l}\text { Si hay participación extranjera en la composición del capital de } \\
\text { la empresa. }\end{array}$ \\
\hline Acceso al financiamiento & $\begin{array}{l}\text { Si la empresa obtuvo financiamiento externo entre } 2003 \text { y } \\
2006 .\end{array}$ \\
\hline Vínculos con universidad & $\begin{array}{l}\text { Si la empresa entabló relaciones con alguna universidad } \\
\text { durante } 2006 \text {. }\end{array}$ \\
\hline $\begin{array}{l}\text { Vínculos con cámaras } \\
\text { empresariales }\end{array}$ & $\begin{array}{l}\text { Si la empresa entabló relaciones con cámaras empresariales } \\
\text { durante } 2006 \text {. }\end{array}$ \\
\hline $\begin{array}{l}\text { Vínculos con consultores } \\
\text { externos }\end{array}$ & $\begin{array}{l}\text { Si la empresa entabló relaciones con consultores externos } \\
\text { durante } 2006 \text {. }\end{array}$ \\
\hline Política pública & $\begin{array}{l}\text { Si la empresa ha desarrollado alguna actividad con algún } \\
\text { organismo público durante } 2006 \text {. }\end{array}$ \\
\hline Capacidad de absorción & $\begin{array}{l}\text { Proporción de trabajadores con estudios de profesional técnico } \\
\text { y/o universitarios en la empresa en } 2006 \text {. }\end{array}$ \\
\hline Región & $\begin{array}{l}\text { Variable dummy sobre ubicación regional dentro del territorio } \\
\text { nacional. }\end{array}$ \\
\hline
\end{tabular}

\section{REFERENCIAS BIBLIOGRÁFICAS}

Almeida, Rita, y Fernandes, Ana Margarida (2008), "Openness and Technological Innovations in Developing Countries: Evidence from Firm-Level Surveys", Journal of Development Studies, 44 (5), pp. 701-727.

Andreff, Wladimir (2009), "Outsourcing in the New Strategy of Multinational Companies: Foreign Investment, International Subcontracting and Production Relocation", Papeles de Europa, 18, pp. 5-34.

Bair, Jennifer (2005), "Global Capitalism and Commodity Chains: Looking Back, Going Forward", Competition \& Change, 9 (2), pp. 153-180.

Battisti, Guiliana, y Stoneman, Paul (2010), "How Innovative are UK Firms? Evidence from the Fourth UK Community Innovation Survey on Synergies between Technological and Organizational Innovations", British Journal of Management, 21 (1), pp. 187-206.

Bernard, Andrew, y Jensen, Bradford (1999), "Exceptional Exporter Performance: cause, effect, or both?", Journal of International Economics, 47 (1), pp. 1-25. 
BID (2014), Fábricas sincronizadas: América Latina y el Caribe en la era de las cadenas globales de valor, Washington, DC, Banco Interamericano de Desarrollo.

Clerides, Sofronis K.; Lach, Saul, y Tybout, James R. (1998), "Is Learning by Exporting Important? Micro-Dynamic Evidence from Colombia, Mexico, and Morocco", The Quarterly Journal of Economics, 113 (3), pp. 903-947.

Cohen, Wesley M., y Levinthal, Daniel A. (1990), “Absorptive Capacity: A New Perspective on Learning and Innovation”, Administrative Science Quarterly, 35 (1), pp. 128-152.

Crespi, Gustavo; Criscuolo, Chiara, y Haskel, Jonathan (2008), "Productivity, Exporting, and the Learning-by-Exporting Hypothesis: Direct Evidence from UK Firms", Canadian Journal of Economics/Revue canadienne d'économique, 41 (2), pp. 619-638.

Crespi, Gustavo, y Zuñiga, Pluvia (2012), "Innovation and Productivity: Evidence from Six Latin American Countries”, World Development, 40 (2), pp. 273-290.

Criscuolo, Chiara; Haskel, Jonathan, y Slaughter, Matthew (2010), "Global Engagement and the Innovation Activities of Firm", International Journal of Industrial Organization, 28 (2), pp. 191-202.

Chesnais, Francois (1988), "Multinational Enterprises and the International Diffusion of Technology", en G. Dosi, C. Freeman, R. Nelson, G. Silverberg y L. Soete (eds.), Technical Change and Economic Theory, London, Pinter Publishers, pp. 496-527.

Chudnovsky, Daniel; López, Andrés, y Pupato, Germán (2006), “Innovation and Productivity in Developing Countries: A Study of Argentine Manufacturing Firms' Behavior (1992-2001)", Research Policy, 35 (2), pp. 266-288.

Dunning, John H. (1995), "Reappraising the Eclectic Paradigm in an Age of Alliance Capitalism", Journal of International Business Studies, 26 (3), pp. 461-89.

Damijan, Joze P.; Kostevc, Črt, y Polanec, Saso (2010), "From Innovation to Exporting or Vice Versa?”, World Economy, 33 (3), pp. 374-398.

Feesnstra, Robert C. (1998), "Integration of Trade and Disintegration of Production in the Global Economy", Journal of Economic Perspectives, 12 (4), pp. 31-50.

Gereffi, Gary (1994), “The Organisation of Buyer-Driven Global Commodity Chains: How us Retailers Shape Overseas Production Networks”, en G. Gereffi y M. Korzeniewicz (eds.), Commodity Chains and Global Capitalism, Westport, Praeger, pp. 95-122.

- (1999), "International Trade and Industrial Upgrading in the Apparel Commodity Chain”, Journal of International Economics, 48 (1), pp. 37-70.

Gereffi, Gary; Humphrey, John; Kaplinsky, Raphael, y Sturgeon, Timothy (2001), 
"Introduction: Globalisation, Value Chains and Development", IDs Bulletin, 32 (3), pp. 1-8.

Gereffi, Gary; Humphrey, John, y Sturgeon, Timothy (2005), “The Governance of Global Value Chains", Review of International Political Economy, 12 (1), pp. 78-104.

Giuliani, Elisa; Pietrobelli, Carlo, y Rabellotti, Roberta (2005), "Upgrading in Global Value Chains: Lessons from Latin American Clusters", World Development, 33 (4), pp. 549-573.

Gonçalves, Eduardo; Borges, Mauro, y Negri, Joao de (2008), “Condicionantes de la innovación tecnológica en Argentina y Brasil”, Revista CEPAL, 0 (94), pp. 75-99.

Gorodnichenko, Yury; Svejnar, Jan, y Terrell, Katherine (2010), “Globalization and Innovation in Emerging Markets", American Economic Journal: Macroeconomics, 2 (2), pp. 194-226.

Humphrey, John, y Schmitz, Hubert (2002), "How Does Insertion in Global Value Chains Affect Upgrading in Industrial Clusters?", Regional Studies, 36 (9), pp. 1017-1027.

Kaplinsky, Raphael (2000), "Globalisation and Unequalisation: What Can Be Learned from Value Chain Analysis", The Journal of Development Studies, 37 (2), pp. 117-146.

Kaplinsky, Raphael, y Morris, Mike (2001), A Handbook for Value Chain Research, Institute of Development Studies, University of Sussex. [en línea] Consultado el 22 de junio de 2016, en: http://www.ids.ac.uk/ids/global/pdfs/VchNov01.pdf.

Keller, Wolfgang (2004), "International Technology Diffusion”, Journal of Economic Literature, 42 (3), pp. 752-782.

Kumar, Nagesh, y Aggarwal, Aradhna (2005), "Liberalization, Outward Orientation and In-House r\&d Activity of Multinational and Local Firms: A Quantitative Exploration for Indian Manufacturing”, Research Policy, 34 (4), pp. 441-460.

Langlois, Richard N. (2003), "The Vanishing Hand: the Changing Dynamics of Industrial Capitalism", Industrial and Corporate Change, 12 (2), pp. 351-385.

Lavarello, Pablo (2004), "Estrategias empresariales y tecnológicas de las firmas multinacionales de las industrias agroalimentarias argentinas durante los años noventa", Desarrollo Económico, 44 (174), pp. 231-260.

Long, J. Scott (1997), Regression Models for Categorical and Limited Dependent Variables, London, Sage Publications.

Lundvall, Bengt-Ake (ed.) (1992), National Systems of Innovation: Towards a Theory of Innovation and Interactive Learning, London, Pinter.

Mancini, Matías, y Lavarello, Pablo (2011), "Capacidades innovativas e inserción de las pymes en subsistemas productivos de la provincia de Buenos Aires", ponencia 
en el XIV Congreso Latino-Iberoamericano de Gestión Tecnológica-ALTEC 2011, Lima, Perú.

Memedovic, Olga (2004), "Inserting Local Industries into Global Value Chains and Global Production Networks: Opportunities and Challenges for Upgrading", working paper, United Nations Industrial Development Organization.

Morrison, Andrea; Pietrobelli, Carlo, y Rabellotti, Roberta (2008), "Global Value Chains and Technological Capabilities: A Framework to Study Learning and Innovation in Developing Countries", Oxford Development Studies, 36 (1), pp. 39-58.

Pavitt, Keith (1984), "Sectoral Patterns of Technical Change: Towards a Taxonomy and a Theory", Research Policy, 13 (6), pp. 343-373.

Pietrobelli, Carlo, y Rabellotti, Roberta (2004), Upgrading in Clusters and Value Chains in Latin America. The Role of Policies, Washington, DC, Inter-American Development Bank.

Pietrobelli, Carlo, y Saliola, Federica (2008), "Power Relationships Along the Value Chain: Multinational Firms, Global Buyers and Performance of Local Suppliers", Cambridge Journal of Economics, 32 (6), pp. 947-962.

Porter, Michael E. (1986), "Changing Patterns of International Competition”, California Management Review, 28 (2), pp. 9-40.

Salomon, Robert M., y Shaver, Myles J. (2005), "Learning by Exporting: New Insights from Examining Firm Innovation", Journal of Economics \& Management Strategy, 14 (2), pp. 431-460.

Schmitz, Hubert, y Knorringa, Peter (2000), "Learning from Global Buyers", The Journal of Development Studies, 37 (2), pp. 177-205.

Williamson, Oliver E. (1979), "Transaction-Cost Economics: The Governance of Contractual Relations", Journal of Law and Economics, 22 (2), pp. 233-261.

Yoguel, Gabriel; Borello, José Antonio, y Erbes, Analia (2009), “Argentina: cómo estudiar y actuar sobre los sistemas locales de innovación”, Revista de la CEPAL, 0 (99), pp. 65-82. 